\title{
Bioconversion of Crude Glycerol into 1,3-Propanediol(1,3-PDO) with Bioelectrochemical System and Zero-Valent Iron Using Klebsiella pneumoniae L17
}

\author{
Da Seul Kong ${ }^{1}$, Eun Joo Park ${ }^{1}$, Sakuntala Mutyala ${ }^{1}$, Minsoo Kim ${ }^{1}$, Yunchul Cho ${ }^{2}$, Sang Eun Oh ${ }^{3}$, \\ Changman Kim ${ }^{4,5, * \mathbb{D}}$ and Jung Rae Kim ${ }^{1, * \mathbb{D}}$ \\ 1 School of Chemical Engineering, Pusan National University, Busan 46241, Korea; \\ dasuel12@naver.com (D.S.K.); unic7391@naver.com (E.J.P.); sakuntala1819@gmail.com (S.M.); \\ minsu9000@naver.com (M.K.) \\ 2 Department of Environmental Engineering, Daejeon University, 62 Daehak-ro, Dong-gu, \\ Daejeon 34520, Korea; ycho@dju.ac.kr \\ 3 Department of Biological Environment, Kangwon National University, Gangwondo, \\ Chuncheon 200-701, Korea; ohsangeun@kangwon.ac.kr \\ 4 Advanced Biofuel and Bioproducts Process Development Unit, Lawrence Berkeley National Laboratory, \\ Emeryville, CA 94608, USA \\ 5 Department of Biotechnology and Bioengineering, Chonnam National University, Gwangju 61188, Korea \\ * Correspondence: cmkim@jnu.ac.kr (C.K.); j.kim@pusan.ac.kr (J.R.K.); Tel.: +1-510-332-0104 (C.K.); \\ +82-51-510-2393 (J.R.K.); Fax: +82-51-512-8563 (J.R.K.)
}

\section{check for} updates

Citation: Kong, D.S.; Park, E.J.; Mutyala, S.; Kim, M.; Cho, Y.; Oh, S.E.; Kim, C.; Kim, J.R. Bioconversion of Crude Glycerol into

1,3-Propanediol(1,3-PDO) with Bioelectrochemical System and Zero-Valent Iron Using Klebsiella pneumoniae L17. Energies 2021, 14 6806. https://doi.org/10.3390/ en14206806

Academic Editor: Mariusz J. Stolarski

Received: 25 August 2021

Accepted: 13 October 2021

Published: 18 October 202

Publisher's Note: MDPI stays neutra with regard to jurisdictional claims in published maps and institutional affiliations.

Copyright: (c) 2021 by the authors. Licensee MDPI, Basel, Switzerland. This article is an open access article distributed under the terms and conditions of the Creative Commons Attribution (CC BY) license (https:// creativecommons.org/licenses/by/ $4.0 /)$.

\begin{abstract}
Crude glycerol is a major byproduct in the production of biodiesel and contains a large number of impurities. The transformation of crude glycerol into valuable compounds such as 1,3-propanediol (1,3-PDO) using clean and renewable processes, like bioconversion, is an important task for the future of the chemical industry. In this study, 1,3-PDO bioproductions from crude and pure glycerol were estimated as $15.4 \pm 0.8$ and $11.4 \pm 0.1 \mathrm{mmol} / \mathrm{L}$, respectively. Because $1,3-\mathrm{PDO}$ is a reductive metabolite that requires additional reducing energy, external supplements of electron for further improvement of 1,3-PDO biosynthesis were attempted using a bioelectrochemical system (BES) or zero-valent iron (ZVI). The conversions of crude and pure glycerol under electrode and iron-based cultivation were investigated for 1,3-PDO production accompanied by metabolic shift and cell growth. The BES-based conversion produced $32.6 \pm 0.6 \mathrm{mmol} / \mathrm{L}$ of 1,3-PDO with ZVI implementation.
\end{abstract}

Keywords: crude glycerol; Klebsiella pneumoniae L17; 1,3-propanediol (1,3-PDO); bioelectrochemical system (BES); zero-valent iron (ZVI)

\section{Introduction}

Crude glycerol, a major byproduct of the biodiesel process in the transesterification of animal fats and vegetable oils, has been widely examined for waste conversion to produce value-added chemicals [1,2]. During every $9 \mathrm{~kg}$ of biodiesel synthesis, approximately $1 \mathrm{~kg}$ of crude glycerol is produced as a byproduct. The composition of crude glycerol is mostly glycerol (over 92\%), with some impure ingredients such as water, methanol, and organic matters [3]. Although several successful glycerol conversion studies have been reported, further improvement is still required because of the relatively high purification cost [4]. Pure glycerol costs 7.5 times more than its crude counterpart at the current market price (Table 1) [2,5]; this implies that the additional glycerol purification process is complicated and expensive. Therefore, several studies have reported direct bioconversion of nonpurified crude glycerol to value-added products, such as hydrogen, methane, fatty acids, and 1,3-propanediol [6-11]. 
Table 1. Glycerin technology of economic value. The market price of crude glycerol, pure glycerol, and 1,3-propanediol [2].

\begin{tabular}{cccc}
\hline & Crude Glycerol & Pure Glycerol & 1,3-Propanediol \\
\hline Price (USD/ton) & 170 & 1275 & 2000 \\
\hline
\end{tabular}

1,3-Propanediol (1,3-PDO; $\left.\mathrm{C}_{3} \mathrm{H}_{8} \mathrm{O}_{2}\right)$ is an important three-carbon platform chemical for additional chemical synthesis [10], mainly used in the synthesis of polytrimethylene terephthalate (PTT) [12]. The 1,3-PDO market is rapidly growing and expected to reach $\$ 6.2$ million by 2021 (146.0 kilotons and 225.9 kilotons by 2014 and 2021, respectively) [13]. Interestingly, biological 1,3-PDO production processes are already competitive against chemical catalytic processes; several industrially applicable bioconversion processes were reported [12,14-16]. Microbial metabolic pathways for the synthesis of 1,3-PDO from glycerol consist of only two-step reactions: glycerol dehydration to 3-HPA (3-hydroxypropionaldehyde with coenzyme $\mathrm{B}_{12}$ as a co-factor; $\mathrm{C}_{3} \mathrm{H}_{6} \mathrm{O}_{2}$ ) and then 3-HPA reduction to 1,3-PDO with NADH as a redox co-factor $[13,17]$. In other words, NADH regeneration and/or supply of additional reduction energy are essential for the bioconversion of glycerol to 1,3-PDO, based on the stoichiometric net calculation.

Klebsiella pneumoniae is a natural 1,3-PDO producer, having several advantages in 1,3-PDO production [17]. K. pneumoniae has highly active glycerol assimilation metabolism in anoxic conditions and well-developed natural 1,3-PDO production pathways [13,17-21]. Several studies reported that electron transfer from electrode to bacteria induced the metabolic shifts of K. pneumoniae L17 in a bioelectrochemical system (BES) and increased 1,3-PDO production [13,21,22]. Similarly, zero-valent iron (ZVI) was also demonstrated as the feasible electron source for a K. pneumoniae strain for enhancement of 1,3-PDO production $[23,24]$.

In this study, we tried to produce 1,3-PDO using non-purified crude glycerol with a K. pneumoniae L17 strain. Moreover, the supplement of an additional electron transfer via ZVI oxidation and the cathode of a bioelectrochemical system was proposed to improve 1,3-PDO productivity. Not only enhanced 1,3-PDO production titer but also metabolic fluxes were identified to understand the effect of both glycerol impurity and additional electron sources by stoichiometric analysis. This study could suggest the possibility of further improvements of the biological 1,3-PDO production process by using non-purified crude glycerol and additional energy sources.

\section{Materials and Methods}

\subsection{Strain and Cultivation}

K. pneumoniae L17 was purchased from the China Center for Type Culture Collection (CCTCC). The experimental fermentation medium contains the following composition (per liter): $18.04 \mathrm{~g} \mathrm{~K}_{2} \mathrm{HPO}_{4}, 1.804 \mathrm{~g} \mathrm{KH}_{2} \mathrm{PO}_{4}, 1 \mathrm{~g} \mathrm{NaCl}, 1 \mathrm{~g}$ yeast extract, $0.25 \mathrm{~g} \mathrm{MgSO}_{4} \cdot 7 \mathrm{H}_{2} \mathrm{O}$, $9.2 \mathrm{~g}$ pure glycerol or $10 \mathrm{~g}$ crude glycerol. To adjust media $\mathrm{pH}$ to $7.5,10 \% \mathrm{HCl}$ and $5 \mathrm{~N}$ $\mathrm{NaOH}$ were used. For exogenic electron supply (70 mesh powder, $<212$ micrometers, ACROS), $0.5 \mathrm{~g}$ of zero-valent iron (ZVI) was added. K. pneumoniae L17 (hereinafter L17) was cultivated in a shaking incubator at $170 \mathrm{rpm}, 30^{\circ} \mathrm{C}$. Aerobic cultivation was carried out in $250 \mathrm{~mL}$ flasks with sponge caps, whereas a serum bottle $(200 \mathrm{~mL})$ was used for anaerobic cultivation after $10 \mathrm{~min}$ of nitrogen purging. Initial cell density was adjusted to $0.05 \mathrm{OD}_{600}$.

\subsection{BES Configuration and Operation}

H-type 2-chamber BES reactors were used according to procedures described elsewhere [22]. Anode and cathode chambers $(310 \mathrm{~mL}$ each) were connected with a glass tube bridge and a proton exchange membrane (PEM, Nafion 117, Dupont, Wilmington, DE, USA). Carbon felt $(2.5 \times 5 \mathrm{~cm}$, Nara Cell-Tech Co., Seoul, Korea) was used for both the anode and cathode. $\mathrm{A} \mathrm{Ag} / \mathrm{AgCl}$ reference electrode was attached to the cathode chamber. The BES reactor was pre-washed with a $10 \% \mathrm{HCl}$ and $5 \mathrm{~N} \mathrm{NaOH}$ solution and sterilized with 
an autoclave $\left(121^{\circ} \mathrm{C}, 15 \mathrm{~min}\right)$. After sterilization, the cathode chamber was filled with a growth medium, and the anode chamber was occupied with $50 \mathrm{mM}$ ferrous sulfate hydrate in a $100 \mathrm{mM}$ potassium phosphate solution ( $\mathrm{pH}$ 7.5). K. pneumoniae L17 was pre-cultured in an LB medium overnight and then reactivated in a fermentation medium for $12 \mathrm{~h}$. The cathode chamber was inoculated with pre-cultured L17 (initial OD $600=0.05$ ). Ampicillin was added to the anode and cathode chambers $(100 \mu \mathrm{m})$ to prevent contamination.

BES reactors were placed in an incubator $\left(30^{\circ} \mathrm{C}\right)$ on a stir plate $(100 \mathrm{rpm})$. Both anode and cathode chambers were purged continuously with nitrogen gas (99.9\%) to maintain anaerobic conditions. The chronoamperometry (-0.7 V vs. Ag/ AgCl) method was used from a potentiostat (WBCS3000Lee32, WonA Tech, Seoul, Korea) to continuously apply potential externally to the cathode as a working electrode.

\subsection{Analytical Methods}

Metabolite production and optical density $\left(\mathrm{OD}_{600}\right)$ were determined using a fermentation broth sample from the flask at $0,5,10$, and $24 \mathrm{~h}$. OD 600 was measured using UV-Vis spectrophotometer (Optizen POP, Keen Innovative Solutions, Daejeon, Korea) at $600 \mathrm{~nm}$. For HPLC analysis, the liquid samples were centrifuged at 12,000 rpm for $10 \mathrm{~min}$. Then, supernatants were filtered using a syringe filter. The filtered samples were analyzed to identify the metabolite concentrations by HPLC (HP 1160 series, Agilent Technologies, Santa Clara, CA, USA) equipped with a $300 \times 7.8 \mathrm{~mm}$ Aminex HPX-87H (Bio-Rad, Hercules, CA, USA) column at $65^{\circ} \mathrm{C}$ and a refractive index (RI) and photodiode array (PDA) detector, using $2.5 \mathrm{mM} \mathrm{H}_{2} \mathrm{SO}_{4}$ as the mobile phase (flow rate $=0.5 \mathrm{~mL} / \mathrm{min}$ ).

\subsection{Metabolic Flux Analysis (MFA)}

The glycerol metabolic flux analysis (MFA) was investigated as previously described [22]. A total of 63 equations have been implemented to determine the metabolic flux, the EMP pathway, PP pathway, tricarboxylic acid cycle (TCA cycle), pyruvate metabolism, energy metabolism, transport reaction, cell growth flux, and electron excretion pathway (Table S1). All the equations for the undetermined metabolic pathways were solved by linear optimization using the MetaFluxNet program [25].

\section{Results and Discussion}

\subsection{1,3-PDO Production in Flask Experiments}

Aerobic and anaerobic flask experiments for 1,3-PDO bioconversion by K. pneumoniae L17 were conducted using pure and crude glycerol (100 mM) (Figure 1A). Most glycerol was consumed within $24 \mathrm{~h}$ in all conditions, even though the aerobic glycerol consumption rate seemed relatively higher than anaerobic fermentations. Under aerobic conditions, 1,3-PDO productions were much lower as $3.1 \pm 0.1$ and $2.8 \pm 0.1 \mathrm{mM}$ from crude and pure glycerol, respectively (Figure 1B). Previous reports determined that oxygen can strongly interrupt not only glycerol dehydratase ( $\mathrm{dhaB})$ but also coenzyme $\mathrm{B}_{12}$ synthesis, which is utilized as an essential co-factor for DhaB in the K. pneumoniae strain. On the other hand, 1,3-PDO synthesis was significantly higher in anaerobic conditions as $15.4 \pm 0.1$ and $11.4 \pm 0.9 \mathrm{mM}$ from crude and pure glycerol, respectively (Figure 1B). Byproduct formations were illustrated in Figure 1C,D. Ethanol productions were relatively higher in anaerobic conditions; acetate synthesis was significantly higher in aerobic conditions. Interestingly, relatively higher 1,3-PDO productions were obtained from crude glycerol fermentation in both aerobic and anaerobic conditions. It is supposed that the potential organic and inorganic ingredients contained in crude glycerol (e.g., $\mathrm{Na}, \mathrm{Ca}, \mathrm{K}, \mathrm{Mg}$, P, S, and unidentified organic matters) positively influenced

Different concentrations of glycerol $(100,200,500$, and $1000 \mathrm{mM})$ were added to anaerobic flasks to identify the effect of initial substrate concentrations with pure glycerol in 1,3-PDO production (Figure 2). After 24 h, 100, 93.8, 60.7, and 23.2\% of glycerol were consumed in 100, 200, 500, and $1000 \mathrm{mM}$ pure glycerol bottles, respectively (Figure 2A). 1,3-PDO productions were determined as $11.4 \pm 0.1,23.3 \pm 1.1,49.0 \pm 1.6$, 
and $74.1 \pm 2.9 \mathrm{mM}$ in 100, 200, 500, and $1000 \mathrm{mM}$ glycerol flasks, respectively (Figure 2B). The final cell densities identified as $1.9 \pm 0.02,2.0 \pm 0.01,1.5 \pm 0.0$, and $1.5 \pm 0.0 \mathrm{mM}$ from $100,200,500$, and $1000 \mathrm{mM}$, respectively (Figure 2C). The other byproduct production was presented in Figure S1.

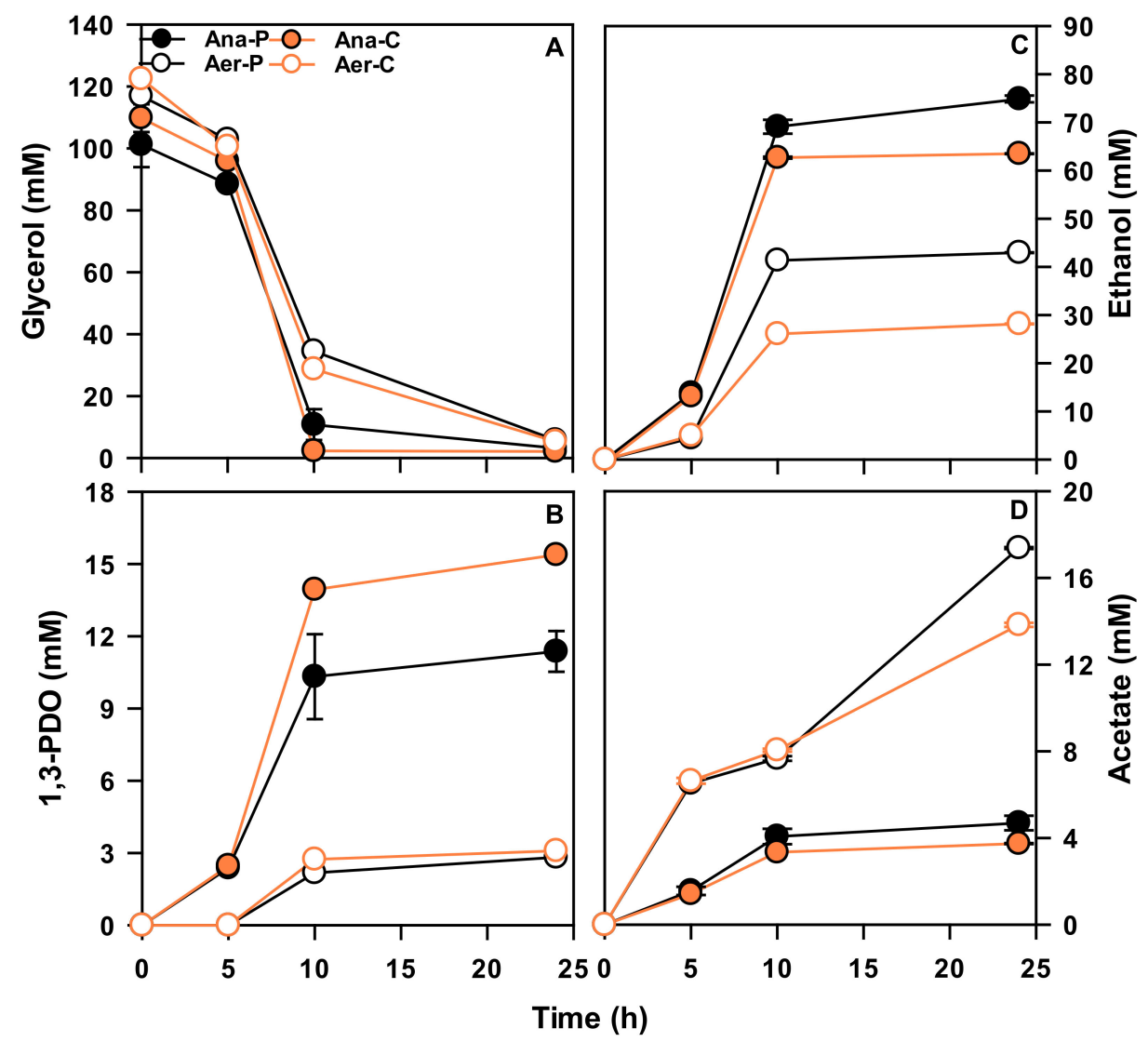

Figure 1. Productivity of 1,3-PDO, ethanol, and acetate according to oxygen condition using crude and pure glycerol. (A) Glycerol consumption and productivity of (B) 1,3-PDO, (C) ethanol, and (D) acetate. Pure glycerol conversion in anaerobic conditions, crude glycerol conversion in anaerobic conditions, pure glycerol conversion in aerobic conditions, and crude glycerol conversion in aerobic conditions expressed as Ana-P, Ana-C, Aer-P, and Aer-C, respectively.

Glycerol is usually considered a reduced substrate in comparison with glucose. Thus, anaerobic glycerol oxidation can elevate the cellular $\mathrm{NADH} / \mathrm{NAD}^{+}$ratio and then shift metabolic fluxes. Under anaerobic conditions, a high concentration of initial glycerol induced overflow metabolism toward reductive pathways in Klebsiella species, resulting in increased 1,3-PDO production yield [27,28]. Figure 2D presented 1,3-PDO production yield. The fermentation result indicates glycerol-derived overflow metabolism with higher glycerol concentration (in $1000 \mathrm{mM}$ glycerol fermentation) in the K. pneumoniae L17 strain. According to overflow metabolism, glycerol consumption, 1,3-PDO production, and cell growth seemed to be reduced after $24 \mathrm{~h}$ (Figure 2C).

1,3-PDO production using crude glycerol was attempted with different concentrations $(100,200,500$, and $1000 \mathrm{mM})$ (Figure 3). Glycerol consumption rates, within $24 \mathrm{~h}$, presented as $100.0,63.9,33.6$, and $18.9 \%$ with $100,200,500$, and $1000 \mathrm{mM}$, respectively (Figure 3A). 1,3-PDO productions were determined as $16.1 \pm 0.3,28.8 \pm 0.2,12.6 \pm 0.4$, and $13.1 \pm 0.1 \mathrm{mM}$ with 100, 200, 500, and $1000 \mathrm{mM}$ of crude glycerol (Figure 3B). Interestingly, significantly lower glycerol consumption and 1,3-PDO production rates were identified in high-crude glycerol conditions, 500 and $1000 \mathrm{mM}$. In addition, cell density was presented as significantly inhibited (lower than $0.1 \mathrm{OD}_{600}$ ). This might be the toxic effect of micronutrients or methanol added as the catalyst in biodiesel production [29,30]. 1,3-PDO 
production yields are illustrated in Figure 3D. Although high concentrations interrupted glycerol metabolism by overflow metabolism and/or toxicity, relatively higher 1,3-PDO production yields were identified in 100 and $200 \mathrm{mM}$ crude glycerol fermentation compared with pure glycerol fermentation (Table 2). In crude glycerol, micronutrients exist, such as fatty acids, magnesium, zinc, and iron, which can help anoxic metabolism by utilizing cell components or co-factors [26]. Because large-scale 1,3-PDO biosynthesis generally uses the constant glycerol concentration (lower than $200 \mathrm{mM}$ ), unpurified glycerol can be directly applicable to 1,3-PDO production [11-13,23].
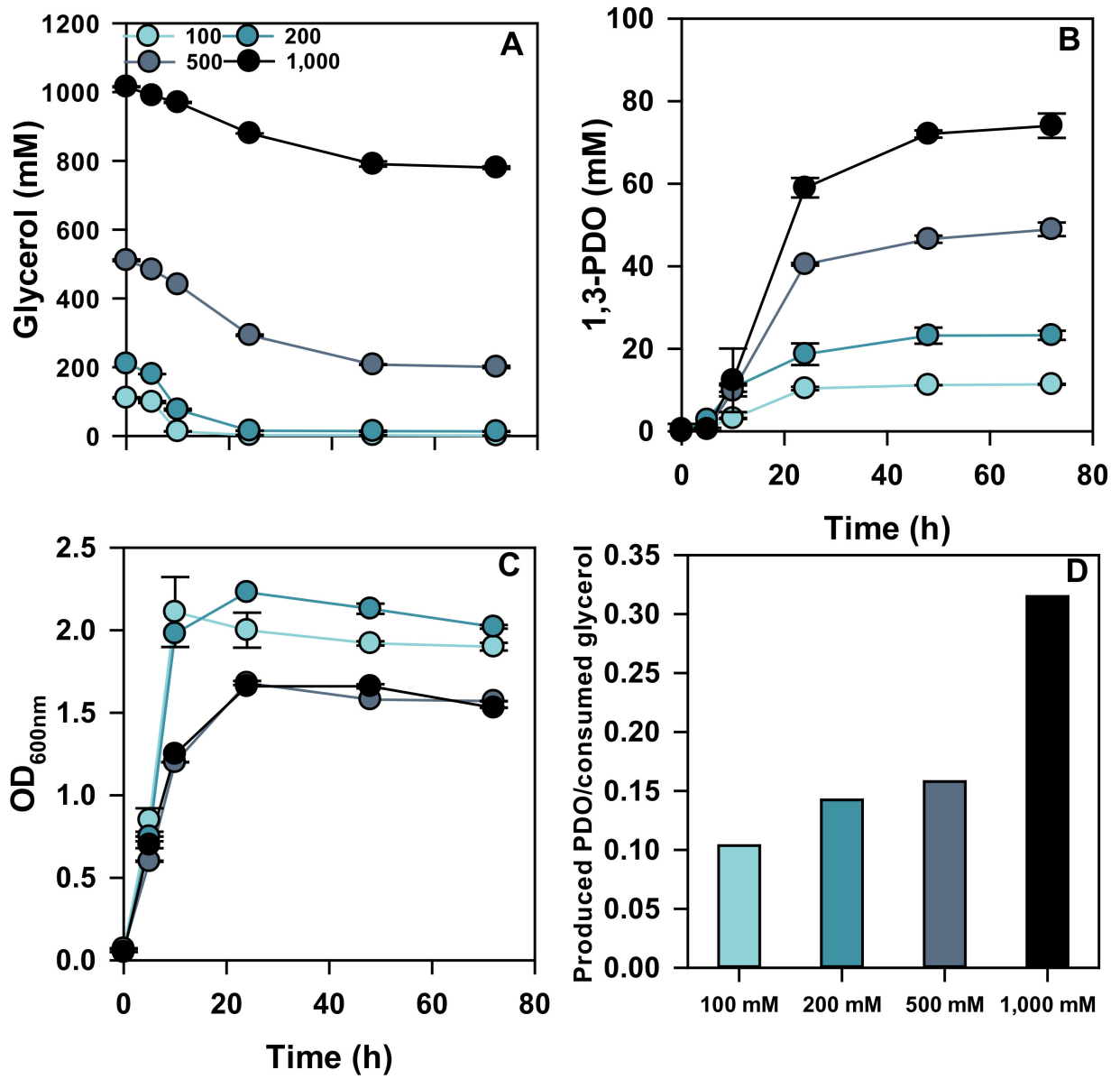

Figure 2. Production difference due to pure glycerol concentration 100, 200, 500, and $1000 \mathrm{mM}$. (A) Glycerol consumption, (B) 1,3-PDO production, (C) optical density (600 nm), and (D) 1,3-PDO production yield $(\mathrm{mol} / \mathrm{mol})$.

Table 2. Production difference due to pure and crude glycerol concentration 100, 200, 500, and $1000 \mathrm{mM}$.

\begin{tabular}{|c|c|c|c|c|}
\hline \multirow{3}{*}{ Type of Glycerol } & Initial Glycerol & Glycerol & 1,3-PDO & \multirow{3}{*}{$\begin{array}{c}\text { Produced PDO/ } \\
\text { Consumed Glycerol Ratio }\end{array}$} \\
\hline & Concentration & Consumption & Production & \\
\hline & $(\mathrm{mM})$ & $(\mathrm{mM})$ & $(\mathrm{mM})$ & \\
\hline \multirow[t]{4}{*}{ Pure glycerol } & 100 & $110.2 \pm 0.1$ & $11.4 \pm 0.1$ & 0.10 \\
\hline & 200 & $197.6 \pm 1.0$ & $23.3 \pm 1.1$ & 0.14 \\
\hline & 500 & $310.0 \pm 3.6$ & $49.0 \pm 1.7$ & 0.16 \\
\hline & 1000 & $235.3 \pm 3.8$ & $74.1 \pm 3.0$ & 0.31 \\
\hline \multirow[t]{4}{*}{ Crude glycerol } & 100 & $119.6 \pm 0.1$ & $16.1 \pm 0.3$ & 0.15 \\
\hline & 200 & $132.9 \pm 2.9$ & $28.8 \pm 0.2$ & 0.29 \\
\hline & 500 & $168.2 \pm 7.4$ & $12.6 \pm 0.4$ & 0.06 \\
\hline & 1000 & $191.7 \pm 2.4$ & $13.1 \pm 0.1$ & 0.07 \\
\hline
\end{tabular}



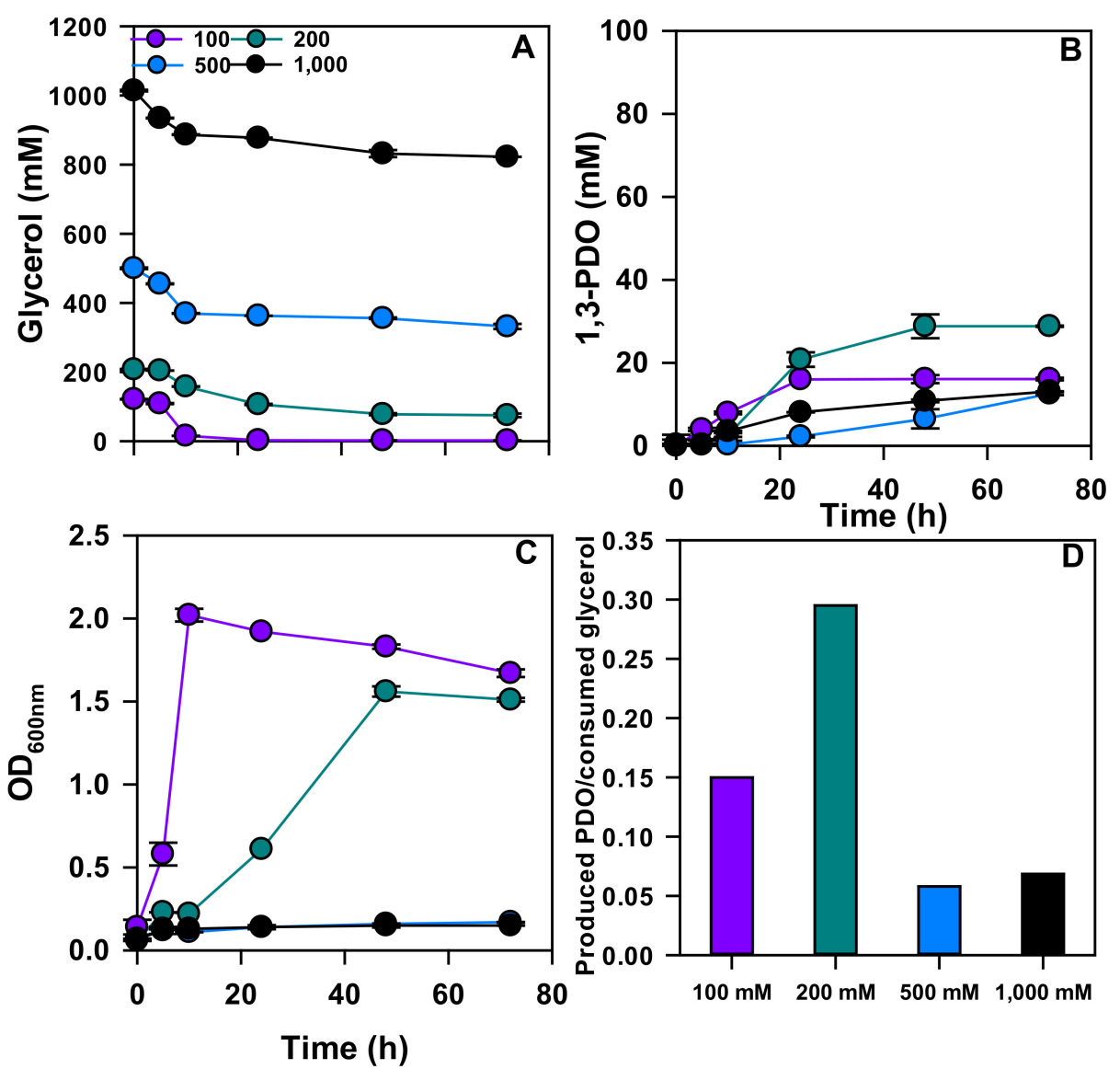

Figure 3. Production difference due to crude glycerol concentration 100, 200, 500, and $1000 \mathrm{mM}$. (A) Glycerol consumption, (B) 1,3-PDO production, (C) optical density (600 nm), and (D) 1,3-PDO production yield ( $\mathrm{mol} / \mathrm{mol})$.

\subsection{Flux Balance Analysis (FBA) of Crude and Pure Glycerol}

To understand the metabolic dynamics of K. pneumoniae L17 between pure and crude glycerol $(100 \mathrm{mM})$, stoichiometric and metabolic flux balance analyses were conducted (Figure 4). Glycerol metabolism can be categorized as oxidation and reduction, referred to as glycerol oxidative and reductive pathways, respectively. In the fermentation flask with pure glycerol as a substrate, the ratio between glycerol oxidative and reductive pathways was presented as $81: 19$, whereas the metabolic flux seemed to be shifted toward more reduction pathways (62:38) when crude glycerol was used as a sole carbon source instead of pure glycerol. 1,3-PDO and ethanol are major metabolites of anaerobic glycerol metabolism in K. pneumoniae strains, representing oxidation and reduction pathways. Although both metabolites are synthesized by NADH-consuming aldehyde reductases (propanediol aldehyde reductase or acetaldehyde reductase for 1,3-PDO or ethanol, respectively), net NADH balances (from glycerol to products) implied that 1,3-PDO synthesis (net -1 NADH) would be more effective to reduce cellular redox balance than ethanol synthesis (net $0 \mathrm{NADH}$ ) (Equations (1) and (2)) [13].

$$
\begin{gathered}
\text { Glycerol }+\mathrm{NADH} \rightarrow 1,3-\mathrm{PDO}+\mathrm{NAD}^{+}+\mathrm{H}_{2} \mathrm{O} \\
2 \text { Glycerol } \rightarrow \text { 2Ethanol }+\mathrm{H}_{2}+2 \mathrm{CO}_{2}
\end{gathered}
$$

This metabolic shift indicates that intracellular metabolism of K. pneumoniae L17 was significantly affected by minor components contained in crude glycerol for several reasons. Even after the extraction process of biofuel, organic materials still existed, such as free fatty acids (FFA), soaps, and fatty acid methyl esters (FAMEs). These could be utilized 
as cell components; thus, bacteria can reduce glycerol oxidative pathways to synthesize additionally. Another hypothesis is that providing multiple substrates (e.g., sugar) can increase carbon flux starting from DHAP. This can over stack glycerol oxidative pathway intermediates, or the anaerobic assimilation of other substrates can increase intracellular redox balance $\left(\mathrm{NAD}(\mathrm{P}) \mathrm{H} / \mathrm{NAD}(\mathrm{P})^{+}\right)$. The increase in cellular redox state can induce glycerol reductive metabolism $[14,31]$.
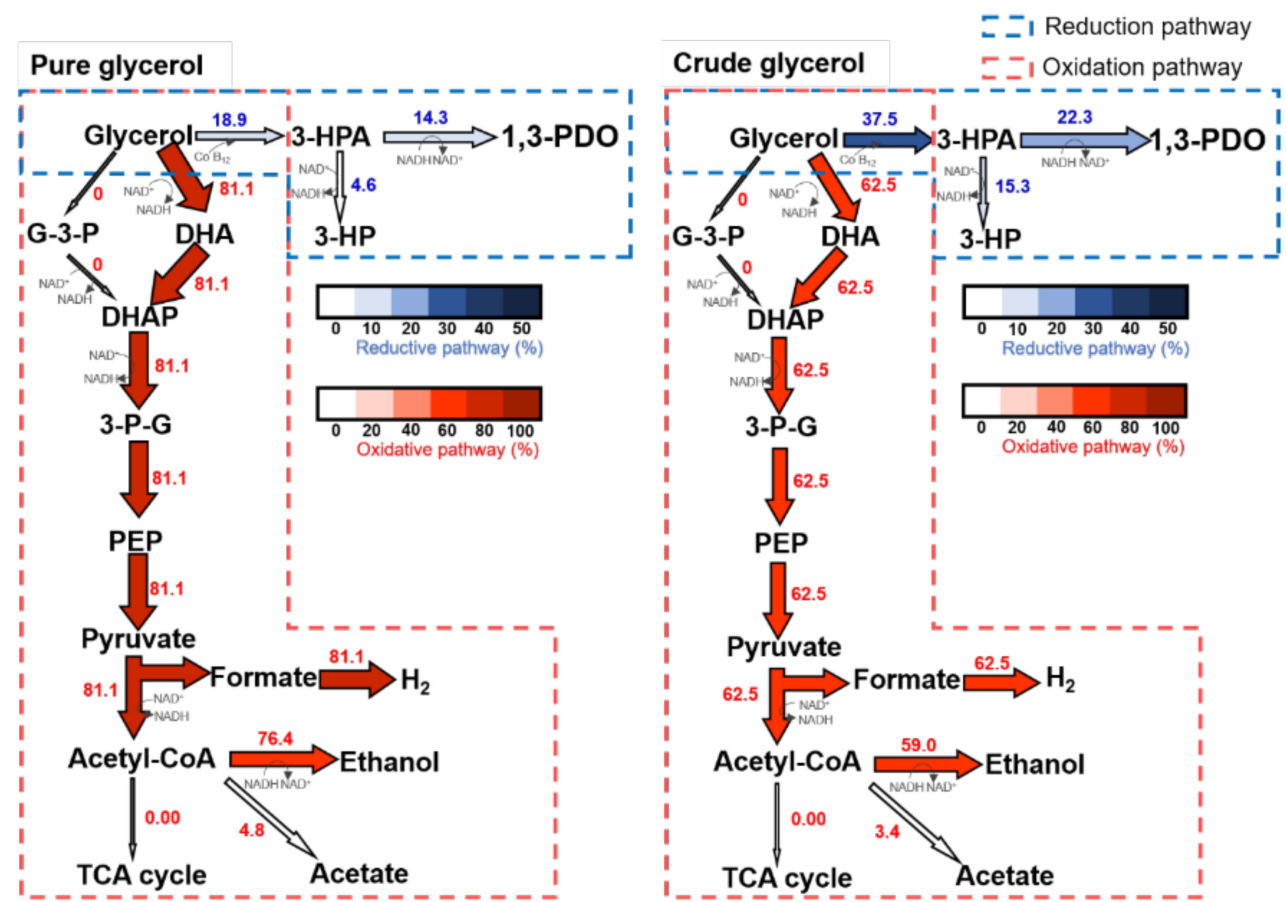

Figure 4. The metabolic flux analysis of crude and pure glycerol was calculated using the meta flux net program.

\subsection{Electron Uptake for Improvement of 1,3-PDO Production}

Previous works have demonstrated that 1,3-PDO production can be improved with additional reducing energy supplies by cathodic electron transfer in BES or oxidation of ZVI [13,32]. 1,3-PDO productions using both $100 \mathrm{mM}$ of crude and pure glycerol were examined in a cathode chamber in BES reactors with $-0.7 \mathrm{~V}$ (vs. $\mathrm{Ag} / \mathrm{AgCl}$ ) potential and nonBES (electrically disconnected reactor). Most glycerol was consumed within $10 \mathrm{~h}$, while different 1,3-PDO productions were identified as $2.1(32.5 \pm 0.6 \mathrm{mM})$ and $2.5(28.3 \pm 0.5 \mathrm{mM})$ times higher than flask fermentation with crude and pure glycerol, respectively (Figure 5). Similarly, 1,3-PDO production increases were determined with $200 \mathrm{mM}$ glycerol substrate as $2.2(76.5 \pm 1.1 \mathrm{mM}$, crude glycerol) and $2.3(67.3 \pm 3.2 \mathrm{mM}$, pure glycerol $)$ in the same BES. Kim et al. suggest that current uptake triggers the metabolic shift toward glycerol reductive metabolism in the K. pneumoniae L17 strain [13]. Even though crude glycerol contained several minor components, this might not affect the electron transferring and/or electrode-driven metabolic shifting in 1,3-PDO production (Figure 6).

Installation of the electrode into the bioreactor enables us to regulate the cellular redox state without chemical additives but brings technical issues, such as bioreactor design and process development. Instead, addition of undissolved iron molecules, such as ZVI, into bioreactors can make similar effects in conventionally used bioreactors or bottles. As the fermentation results with ZVI as the electron donor, $1.9(28.9 \pm 0.2 \mathrm{mM})$ and $2.2(24.8 \pm 1.6 \mathrm{mM})$ times higher 1,3-PDO productions were determined with both crude and pure glycerol substrate, respectively (Figure 5). With the doubled initial glycerol concentration $(200 \mathrm{mM})$, the increase in 1,3-PDO was also presented as $2.5(67.3 \pm 3.2 \mathrm{mM})$ and $2.6(76.5 \pm 1.1 \mathrm{mM})$ times higher with crude and pure glycerol, respectively (Figure 6). The 
results indicate that ZVI can support glycerol reduction via transferring additional reducing energy, both with non-purified and purified glycerol, similar to BES-applied fermentations.

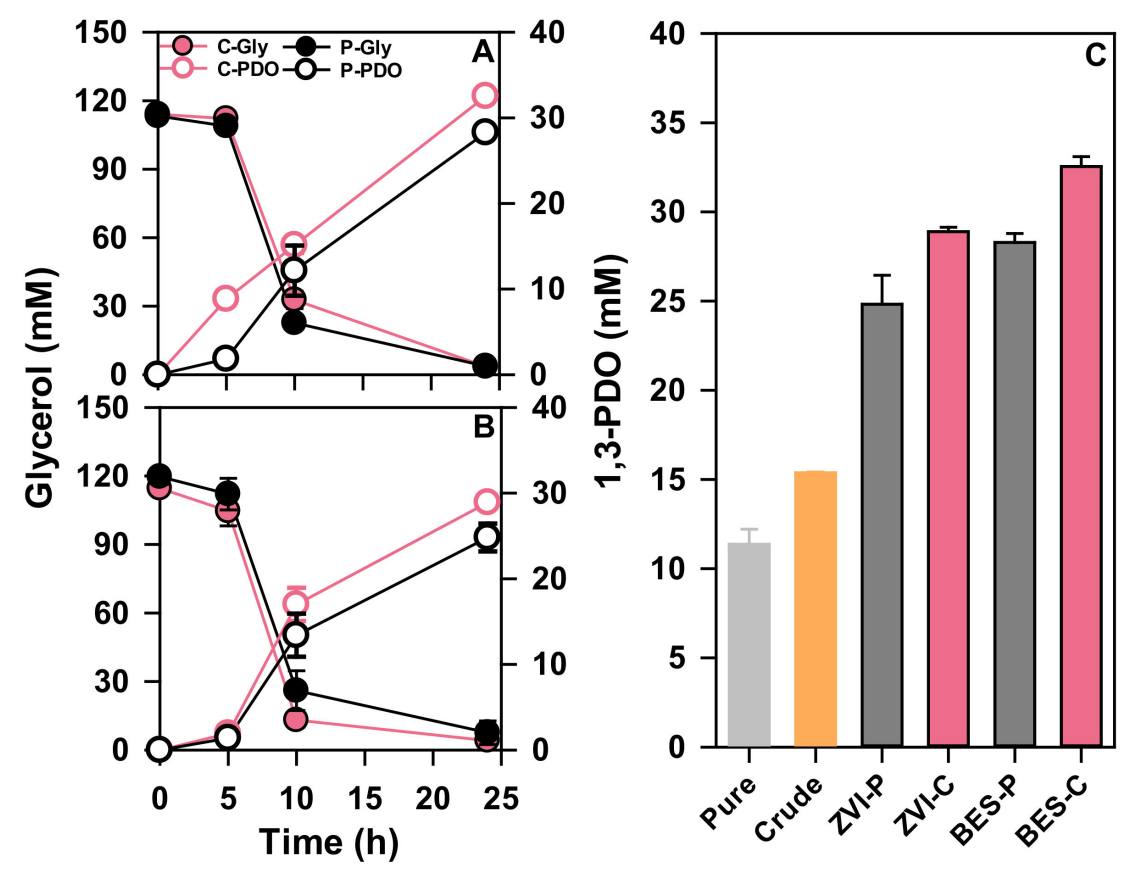

Figure 5. Crude and pure glycerol $(100 \mathrm{mM})$ applied to BES and ZVI. Productivity of 1,3-PDO and glycerol consumption using (A) BES, (B) ZVI, and (C) 1,3-PDO production with and without ZVI and BES for crude and pure glycerol (P: pure glycerol; C: crude glycerol).
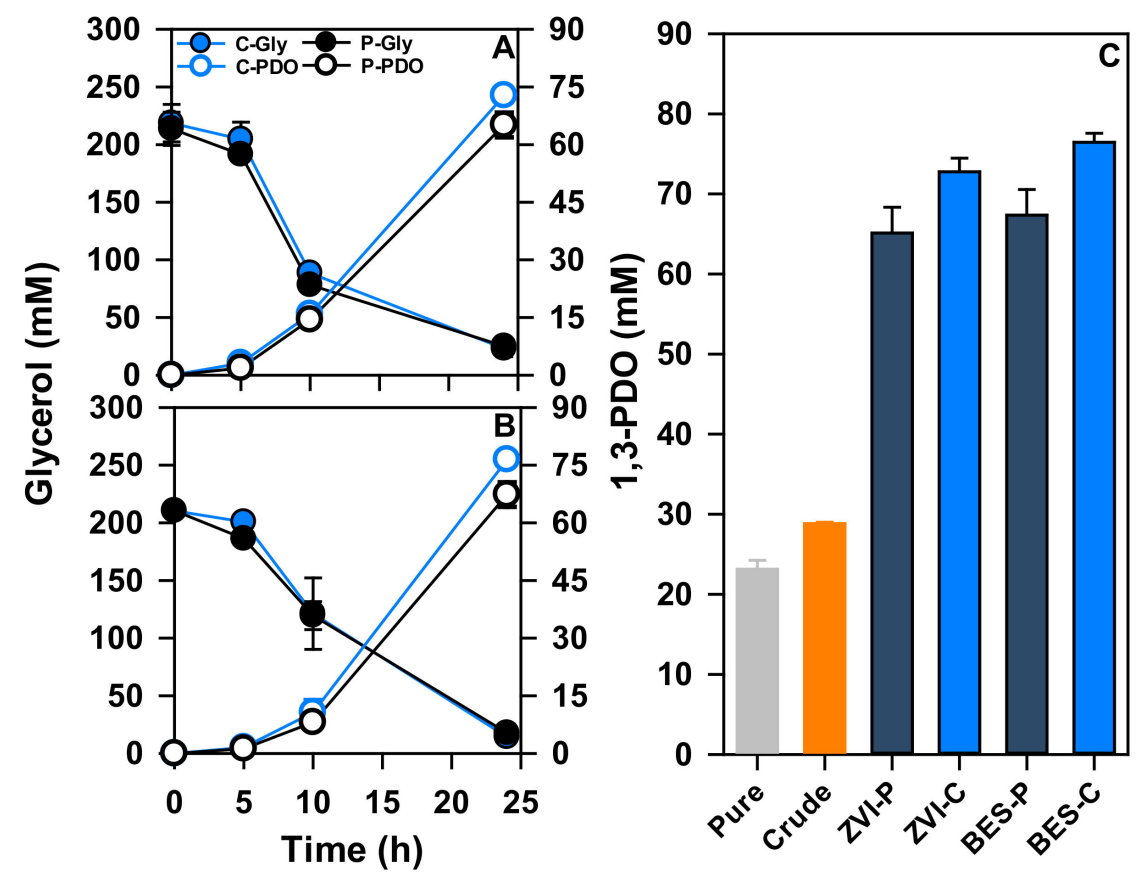

Figure 6. Crude and pure glycerol $(200 \mathrm{mM})$ applied to BES and ZVI. Productivity of 1,3-PDO and glycerol consumption using (A) BES, (B) ZVI, and (C) 1,3-PDO production with and without ZVI and BES for crude and pure glycerol (P: pure glycerol; $\mathrm{C}$ : crude glycerol).

Current 1,3-PDO bioproduction processes have already been well developed; however, it is required to improve the productivity with not only traditional upstream (e.g., strain engineering) and downstream (e.g., process engineering) development but also other 
approaches. Non-purified substrate utilization might be the one option to increase bioconversion efficiency with regard to the economic aspects. Table 1 presented that the price of crude glycerol is just $13 \%$ of the price of pure glycerol; the crude glycerol fermentation process can reduce the fermentation cost by using a much cheaper substrate. Providing additional reducing energy via both cathodic electrodes and metallic granules would be the next step for 1,3-PDO bioproduction because of redox imbalance between the substrate and product. Although there are several demonstrations of the improvement of 1,3-PDO productivity using BES or ZVI, this research presented the applications in non-purified glycerol conversion. The results implied that both electron supply modes can be applied not only in 1,3-PDO production but also in several reductive fermentations using glycerol as a substrate.

\section{Conclusions}

In this study, we examined the 1,3-PDO bioproduction process using non-purified crude glycerol as a substrate. Fermentation results indicated that significantly higher 1,3-PDO production was identified with crude glycerol $(15.4 \pm 0.8 \mathrm{mM})$ compared to pure glycerol $(11.4 \pm 0.1 \mathrm{mM})$. Metabolic flux balance analysis revealed that micronutrients, included in crude glycerol, induced the metabolic shift toward glycerol reductive pathways. Furthermore, additional reducing energy supplemented by cathodic electrodes improved 1,3-PDO production ( $32.5 \pm 0.6$ and $28.3 \pm 0.5 \mathrm{mM}$ with crude and pure glycerol, respectively) or ZVI ( $28.9 \pm 0.2$ and $24.8 \pm 1.6 \mathrm{mM}$ with crude and pure glycerol, respectively). The results demonstrated the possibility of crude glycerol utilization in 1,3-PDO production and further improvement of productivity with BES and ZVI-based bioconversion.

Supplementary Materials: The following are available online at https:/ / www.mdpi.com/article / 10.3390/en14206806/s1, Figure S1: Comparison OD and pH of $100 \mathrm{mM}$ pure and crude glycerol in flask. (A) cell growth (OD) and $\mathrm{pH}$ and (B) lactate production; Table S1: The reactions and results of in silico metabolic flux analysis.

Author Contributions: Investigation, experiment, and writing-original draft, investigation, and analysis, D.S.K.; methodology and analyses, E.J.P., S.M., M.K., Y.C. and S.E.O.; writing-review and editing, J.R.K. and C.K.; supervision, J.R.K. All authors have read and agreed to the published version of the manuscript.

Funding: This study was supported by the Basic Science Research Program (NRF-2019R1A6A3A 12033897) and the Mid-Career Researcher Program (NRF-2021R1A2C200784111) through the National Research Foundation of Korea (NRF), funded by the Ministry of Science, ICT \& Future Planning of Korea, and female graduate student engineering research team system (WISET Contract No. 2021-151), WISET, Korea Foundation for Fostering Women in Science and Technology. This work was also supported by the Korea Institute of Energy Technology Evaluation and Planning (KETEP) grant funded by the Korea government (MOTIE) (20214000000140).

Conflicts of Interest: The authors declare no conflict of interest.

\section{References}

1. Dobson, R.; Gray, V.; Rumbold, K. Microbial utilization of crude glycerol for the production of value-added products. J. Ind. Microbiol. Biotechnol. 2012, 39, 217-226. [CrossRef]

2. Da Silva Ruy, A.D.; Ferreira, A.L.F.; Bresciani, A.É.; de Brito Alves, R.M.; Pontes, L.A.M. Market Prospecting and Assessment of the Economic Potential of Glycerol from Biodiesel. In Biomass; IntechOpen: London, UK, 2020.

3. Chen, C.Y.; Lee, M.H.; Leong, Y.K.; Chang, J.S.; Lee, D.J. Biodiesel production from heterotrophic oleaginous microalga Thraustochytrium sp. BM2 with enhanced lipid accumulation using crude glycerol as alternative carbon source. Bioresour. Technol. 2020, 306, 123113. [CrossRef]

4. Talebian-Kiakalaieh, A.; Amin, N.A.S.; Rajaei, K.; Tarighi, S. Oxidation of bio-renewable glycerol to value-added chemicals through catalytic and electro-chemical processes. Appl. Energy 2018, 230, 1347-1379. [CrossRef]

5. Yang, F.X.; Hanna, M.A.; Sun, R.C. Value-added uses for crude glycerol-a byproduct of biodiesel production. Biotechnol. Biofuels 2012, 5, 13. [CrossRef] [PubMed]

6. Dobrowolski, A.; Drzymala, K.; Mitula, P.; Mironczuk, A.M. Production of tailor-made fatty acids from crude glycerol at low pH by Yarrowia lipolytica. Bioresour.Technol. 2020, 314, 123746. [CrossRef] [PubMed] 
7. Veiga, S.; Faccio, R.; Romero, M.; Bussi, J.J.B. Bioenergy, Utilization of waste crude glycerol for hydrogen production via steam reforming over Ni-La-Zr catalysts. Biomass Bioenergy 2020, 135, 105508. [CrossRef]

8. Sittijunda, S.; Reungsang, A. Methane Production from the Co-digestion of Algal Biomass with Crude Glycerol by Anaerobic Mixed Cultures. Waste Biomass Valoriz. 2020, 11, 1873-1881. [CrossRef]

9. Laura, M.; Monica, T.; Dan-Cristian, V. The effect of crude glycerol impurities on 1,3-propanediol biosynthesis by Klebsiella pneumoniae DSMZ 2026. Renew. Energy 2020, 153, 1418-1427. [CrossRef]

10. Mizielinska, M.; Kowalska, U.; Sobol, M. The continuous bioconversion of glycerol to 1,3-propanediol using immobilized Citrobacter freundii. Rom. Biotech. Lett. 2020, 25, 1448-1455. [CrossRef]

11. De Oliveira Paranhos, A.G.; Silva, E.L.J.B. Bioenergy, Statistical optimization of H2, 1, 3-propanediol and propionic acid production from crude glycerol using an anaerobic fluidized bed reactor: Interaction effects of substrate concentration and hydraulic retention time. Biomass Bioenergy 2020, 138, 105575. [CrossRef]

12. Casali, S.; Gungormusler, M.; Bertin, L.; Fava, F.; Azbar, N. Development of a biofilm technology for the production of 1,3propanediol (1,3-PDO) from crude glycerol. Biochem. Eng. J. 2012, 64, 84-90. [CrossRef]

13. Kim, C.; Lee, J.H.; Baek, J.; Kong, D.S.; Na, J.G.; Lee, J.; Sundstrom, E.; Park, S.; Kim, J.R. Small Current but Highly Productive Synthesis of 1,3-Propanediol from Glycerol by an Electrode-Driven Metabolic Shift in Klebsiella pneumoniae L17. ChemSusChem 2020, 13, 564-573. [CrossRef] [PubMed]

14. Lee, C.S.; Aroua, M.K.; Daud, W.M.A.W.; Cognet, P.; Peres-Lucchese, Y.; Fabre, P.L.; Reynes, O.; Latapie, L. A review: Conversion of bioglycerol into 1,3-propanediol via biological and chemical method. Renew. Sustain. Energy Rev. 2015, 42, 963-972. [CrossRef]

15. Vivek, N.; Pandey, A.; Binod, P. Biological valorization of pure and crude glycerol into 1,3-propanediol using a novel isolate Lactobacillus brevis N1E9.3.3. Bioresour. Technol. 2016, 213, 222-230. [CrossRef] [PubMed]

16. Gungormusler-Yilmaz, M.; Cicek, N.; Levin, D.B.; Azbar, N. Cell immobilization for microbial production of 1,3-propanediol. Crit. Rev. Biotechnol. 2016, 36, 482-494. [CrossRef]

17. Kim, C.; Kim, M.Y.; Michie, I.; Jeon, B.H.; Premier, G.C.; Park, S.; Kim, J.R. Anodic electro-fermentation of 3-hydroxypropionic acid from glycerol by recombinant Klebsiella pneumoniae L17 in a bioelectrochemical system. Biotechnol. Biofuels 2017, 10, 199. [CrossRef]

18. Kumar, V.; Sankaranarayanan, M.; Jae, K.E.; Durgapal, M.; Ashok, S.; Ko, Y.; Sarkar, R.; Park, S. Co-production of 3hydroxypropionic acid and 1,3-propanediol from glycerol using resting cells of recombinant Klebsiella pneumoniae J2B strain overexpressing aldehyde dehydrogenase. Appl. Microbiol. Biotechnol. 2012, 96, 373-383. [CrossRef]

19. Li, X.M.; Zhou, S.G.; Li, F.B.; Wu, C.Y.; Zhuang, L.; Xu, W.; Liu, L. Fe(III) oxide reduction and carbon tetrachloride dechlorination by a newly isolated Klebsiella pneumoniae strain L17. J. Appl. Microbiol. 2009, 106, 130-139. [CrossRef]

20. Liu, T.; Li, X.; Zhang, W.; Hu, M.; Li, F. Fe(III) oxides accelerate microbial nitrate reduction and electricity generation by Klebsiella pneumoniae L17. J. Colloid Interface Sci. 2014, 423, 25-32. [CrossRef]

21. Kim, M.Y.; Kim, C.; Ainala, S.K.; Bae, H.; Jeon, B.H.; Park, S.; Kim, J.R. Metabolic shift of Klebsiella pneumoniae L17 by electrode-based electron transfer using glycerol in a microbial fuel cell. Bioelectrochemistry 2019, 125, 1-7. [CrossRef]

22. Kim, C.; Ainala, S.K.; Oh, Y.K.; Jeon, B.H.; Park, S.; Kim, J.R. Metabolic flux change in Klebsiella pneumoniae L17 by anaerobic respiration in microbial fuel cell. Biotechnol. Bioprocess Eng. 2016, 21, 250-260. [CrossRef]

23. Kong, D.S.; Kim, C.; Song, Y.E.; Baek, J.; Im, H.S.; Kim, J.R. Zero-valent iron driven bioconversion of glycerol to 1, 3-propanediol using Klebsiella pneumoniae L17. J. Process. Biochem. 2021, 106, 158-162. [CrossRef]

24. Im, H.S.; Kim, C.; Song, Y.E.; Baek, J.; Im, C.H.; Kim, J.R. Isolation of Novel CO Converting Microorganism Using Zero Valent Iron for a Bioelectrochemical System (BES). Biotechnol. Bioprocess Eng. 2019, 24, 232-239. [CrossRef]

25. Lee, D.Y.; Yun, H.; Park, S.; Lee, S.Y. MetaFluxNet: The management of metabolic reaction information and quantitative metabolic flux analysis. Bioinformatics 2003, 19, 2144-2146. [CrossRef] [PubMed]

26. Ayoub, M.; Abdullah, A.Z. Critical review on the current scenario and significance of crude glycerol resulting from biodiesel industry towards more sustainable renewable energy industry. Renew. Sustain Energy Rev. 2012, 16, 2671-2686. [CrossRef]

27. Streekstra, H.; Demattos, M.J.T.; Neijssel, O.M.; Tempest, D.W. Overflow Metabolism during Anaerobic Growth of KlebsiellaAerogenes Nctc 418 on Glycerol and Dihydroxyacetone in Chemostat Culture. Arch. Microbiol. 1987, 147, 268-275. [CrossRef]

28. Vemuri, G.N.; Eiteman, M.A.; McEwen, J.E.; Olsson, L.; Nielsen, J. Increasing NADH oxidation reduces overflow metabolism in Saccharomyces cerevisiae. Proc. Natl. Acad. Sci. USA 2007, 104, 2402-2407. [CrossRef]

29. Kumar, N.; Mohapatra, S.K.; Ragit, S.S.; Kundu, K.; Karmakar, R. Optimization of safflower oil transesterification using the Taguchi approach. Petrol. Sci. 2017, 14, 798-805. [CrossRef]

30. Salakkam, A.; Webb, C. The inhibition effect of methanol, as a component of crude glycerol, on the growth rate of Cupriavidus necator and other micro-organisms. Biochem. Eng. J. 2015, 98, 84-90. [CrossRef]

31. Valerio, O.; Horvath, T.; Pond, C.; Misra, M.; Mohanty, A. Improved utilization of crude glycerol from biodiesel industries: Synthesis and characterization of sustainable biobased polyesters. Ind. Crop. Prod. 2015, 78, 141-147. [CrossRef]

32. Zhou, M.; Chen, J.; Freguia, S.; Rabaey, K.; Keller, J. Carbon and electron fluxes during the electricity driven 1,3-propanediol biosynthesis from glycerol. Environ. Sci. Technol. 2013, 47, 11199-11205. [CrossRef] [PubMed] 